UCRL-ID-133503

\title{
Production of High-Value Isotopically Separated Materials
}

\author{
K. F . Scheibner \\ B. Comaskey \\ M. J. Shaw \\ J. G. Wilder
}

February 25, 1999

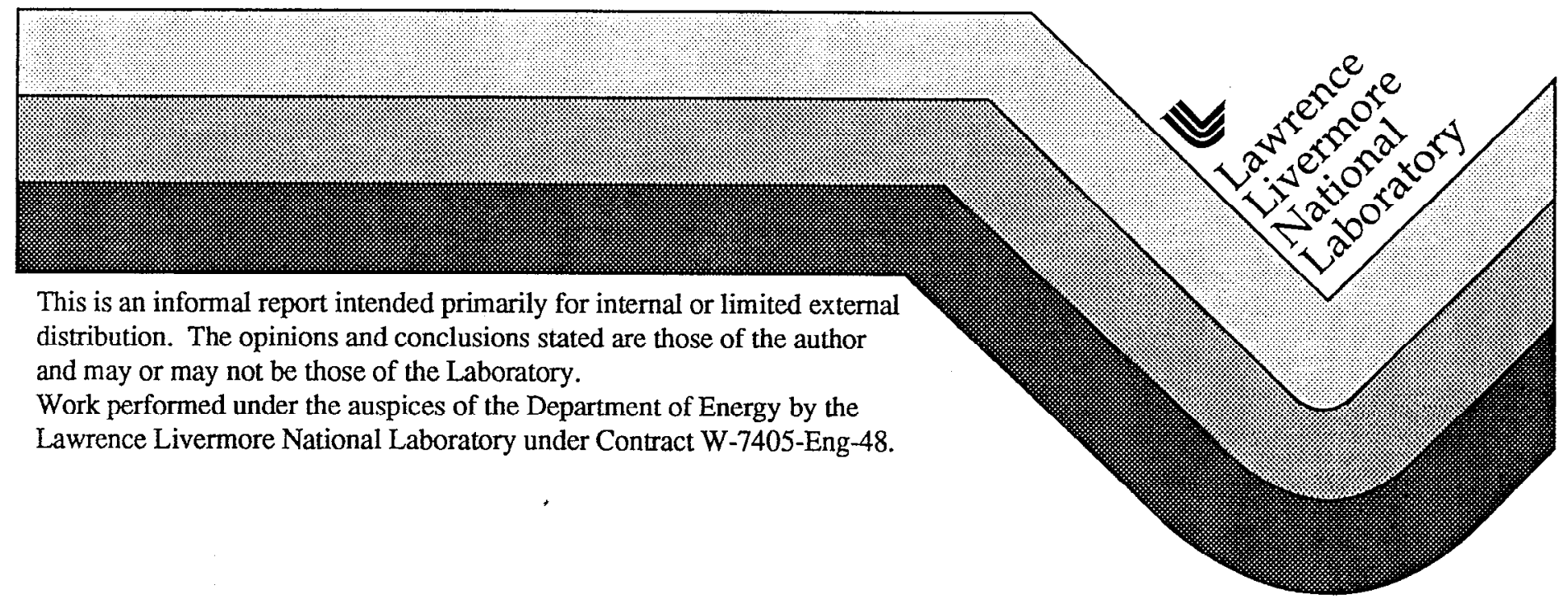




\section{DISCLAIMER}

This document was prepared as an account of work sponsored by an agency of the United States Government. Neither the United States Government nor the University of California nor any of their employees, makes any warranty, express or implied, or assumes any legal liability or responsibility for the accuracy, completeness, or usefulness of any information, apparatus, product, or process disclosed, or represents that its use would not infringe privately owned rights. Reference herein to any specific commercial product, process, or service by trade name, trademark, manufacturer, or otherwise, does not necessarily constitute or imply its endorsement, recommendation, or favoring by the United States Government or the University of California. The views and opinions of authors expressed herein do not necessarily state or reflect those of the United States Government or the University of California, and shall not be used for advertising or product endorsement purposes.

This report has been reproduced directly from the best available copy.

Available to DOE and DOE contractors from the Office of Scientific and Technical Information

P.O. Box 62, Oak Ridge, TN 37831

Prices available from (615) 576-8401, FTS 626-8401

Available to the public from the

National Technical Information Service

U.S. Department of Commerce

5285 Port Royal Rd.,

Springfield, VA 22161 
Fcbruary 25, 1999

\title{
98-ERD-072 Final Report \\ Production of High-Value Isotopically Separated Materials
}

\author{
K. F. Scheibner, B. Comaskey, M. J. Shaw, and J. G. Wilder
}

The purpose of this project was to complete the development of the laser systems and separator systems needed to investigate the potential for the economical separation of high value isotopes used in medical and industrial applications, then demonstrate this separation capability. The project was to focus on the isotopic purification of lead for use as solder in high-end electronics, and on the isotopic enrichment of thallium for medical applications. Ultimately the goal is to demonstrate the economical and technical viability of the technology for lead and thallium and to develop a more general capability for other possible isotope separation missions. Both lead and thallium are useful applications in this context because they require dye lasers, solid-state lasers, and a frequency doubling capability of some of the lasers. This later capability allows access to the wavelength range 250 to $450 \mathrm{~nm}$, with tunable, high-power and high repetition frequency lasers. Until recently, these wavelengths have been largely inaccessible in combination with these other laser characteristics. In addition, up to two new potential laser-isotope separation applications would be conceptually developed through a process of needs analysis and technical feasibility studies.

Because of an unanticipated reduction in the size of the LDRD pool of funds, it was decided not to fully fund this project. However, enough funds were allocated to allow an orderly closeout of the project activities. Two key technical steps in the laser development were accomplished during the closeout phase, both of which are required for lead and thallium isotope separation. The first accomplishment successfully demonstrated the power scalability of a master-oscillator, power amplifier (MOPA) approach to a highpower Ti-sapphire laser host material. The net result output power produced, after a series of amplification stages, was about $50 \mathrm{~W}$ of tunable (red) laser light. In addition, the output power showed no signs of power saturation as the input power was varied. The demonstration verified the design intent of the amplifiers as well as that of the host material. This result is suggestive that greater than $100 \mathrm{~W}$ should easily be achievable from this laser architecturc. Such powers are likely required for many applications such as efficient frequency doubling of red radiation to obtain blue, or near UV radiation, and for medium to large-scale isotope separation. 
The second accomplishment was the successful demonstration of a dye master oscillator that pulse-amplified, at pulse repetition frequencies greater than 10,000 pulses per second, an injected continuous-wave input signal with low-signal gains greater than 500 . This is important to potential isotope separation missions (and other applications) that require narrowly-tuned, high pulse repetition frequency dye laser light and would normally be the first step in a dye MOPA chain to achieve the required high average power. As part of this demonstration the low signal gain was measured as a function of pump pulse power and injected signal strength. Both measurements are required in order to specify the requirements for an eventual system that uses such a master oscillator. 